\title{
The Mechanical Impact of Aerodynamic Stall on Tunnel Ventilation Fans
}

\author{
A. G. Sheard ${ }^{1}$ and A. Corsini ${ }^{2}$ \\ ${ }^{1}$ Fläkt Woods Ltd., Axial Way, Colchester CO4 5ZD, UK \\ ${ }^{2}$ Dipartimento di Ingegneria Meccanica e Aerospaziale, Sapienza University of Rome, Via Eudossiana 18, Rome 00184, Italy
}

Correspondence should be addressed to A. G. Sheard, geoff.sheard@flaktwoods.com

Received 28 August 2011; Revised 3 December 2011; Accepted 7 December 2011

Academic Editor: Ting Wang

Copyright (C) 2012 A. G. Sheard and A. Corsini. This is an open access article distributed under the Creative Commons Attribution License, which permits unrestricted use, distribution, and reproduction in any medium, provided the original work is properly cited.

This paper describes work aimed at establishing the ability of a tunnel ventilation fan to operate without risk of mechanical failure in the event of aerodynamic stall. The research establishes the aerodynamic characteristics of a typical tunnel ventilation fan when operated in both stable and stalled aerodynamic conditions, with and without an anti-stall stabilisation ring, with and without a "nonstalling" blade angle and at full, half, and one quarter design speed. It also measures the fan's peak stress, thus facilitating an analysis of the implications of the experimental results for mechanical design methodology. The paper concludes by presenting three different strategies for tunnel ventilation fan selection in applications where the selected fan will most likely stall. The first strategy selects a fan with a low-blade angle that is nonstalling. The second strategy selects a fan with a high-pressure developing capability. The third strategy selects a fan with a fitted stabilisation ring. Tunnel ventilation system designers each have their favoured fan selection strategy. However, all three strategies can produce system designs within which a tunnel ventilation fan performs reliably in-service. The paper considers the advantages and disadvantages of each selection strategy and considered the strengths and weaknesses of each.

\section{Introduction}

The operating maps of fans and compressors are limited by the occurrence of aerodynamic instabilities when throttling the flow rate. Aerodynamic flow instabilities place considerable mechanical stress on the rotors, which can eventually lead to mechanical failure. Rippl [1] conducted strain gauge measurements on axial compressors, concluding that alternating stress in vanes exceeding stable operation by a factor of five under "rotating stall" conditions. This leads to rapid fatigue failure of the blades. In contrast, a "surge" can lead to the heightening magnitude of bending stress enough to cause a mechanical failure during the surge event itself.

Fan designers classically produce a mechanical design that can withstand the alternating loads imposed on the fan blades associated with rotating stall, and therefore mechanical failure during a stall event is not instantaneous. Aluminium is both low cost and light weight, and consequently the fan designers' preferred choice of blade material. A weakness of aluminium as a structural material is its propensity to fail in fatigue. As such, fan blades that do not typically instantaneously fail during rotating stall fail in fatigue sometime later. The latter failure occurs as a consequence of a fatigue-induced crack initiated in a blade as a consequence of the higher stress during the rotating stall that then goes on to propagate during stable operation.

This paper studies the impact of rotating stall, generally referred to as "aerodynamic stall" within the fan industry, on the mechanical performance of a typical tunnel ventilation fan. The paper starts with a brief literature review relating to fan, blower, and compressor aerodynamic stall before moving on to review the antistall concepts that other scholars have developed in their attempts to improve axial decelerating turbomachinery aerodynamic stability. Placing strain gauges in the location of the fan blades' peak stress, the authors were able to establish the mechanical impact of aerodynamic stall with and without an antistall stabilisation 
ring, with and without a "nonstalling" blade angle and at full, half, and one quarter design speed.

The chosen test matrix incorporated those fan configurations typically utilised in tunnel ventilation applications. The purpose is to establish the increase in peak blade stress associated with transition from stable and stalled aerodynamic conditions. The objective of establishing the increase is to facilitate an analysis of its mechanical consequence. The outcome of the reported research is the identification of change in mechanical safety factors associated with a fan being driven into aerodynamic stall. To the best of the author's knowledge, the results presented in this paper are the first time the effectiveness of an antistall ring has been reported in the literature. The reported research has established that an antistall ring provides some mechanical protection in the event of aerodynamic stall, but not complete protection. The reported research demonstrates the error in the wide-spread assumption amongst industrial fan designers that antistall rings provide complete mechanical protection in the event of aerodynamic stall.

The paper concludes with an analysis of the significance of the results for fan design praxis, recommendations on fan selection strategy and mechanical design methodology for those tunnel ventilation fans applied in selected applications where the fan will most likely stall.

\section{Aerodynamic Stall}

Scholars have examined the detection and analysis of different forms of aerodynamic instability since the 1950s. According to Gravdahl and Egeland [3], two main types of aerodynamic flow instability exist in compressors: (i) "rotating stall" (in which regions of reversed flow occur locally) and (ii) "surge" (which is characterised by periodic backflow over the entire annulus involving violent oscillations in the compression system).

The first of these, "rotating stall," is a mechanism by which the rotor adapts to a reduction in flow rate, which results in circumferentially nonuniform flow patterns rotating in the annulus. Researchers have studied the problem of rotating stall in axial flow compressors in multistage machines [4-6]. The earlier work of Emmons et al. [7] was one of the first attempts to describe the mechanism underlying the propagation of rotating stall. In reviewing the evolution of rotating stall, Cumpsty [8] noted that a drop in overall performance can occur as either a "progressive stall" or an "abrupt stall." Engineers usually associate the former with a part-span stall which results in a small performance reduction; whereas, they associate the later with a full-span stall and a large reduction in performance. Notably, the partspan rotating stall typically occurs in single blade rows [8] and usually leads to more complex disturbances in single rotor or stage machines than in multistage compressors [6].

The fan under scrutiny in the reported research is a typical example from a family of tunnel ventilation fans and has been the subject of recent experimental investigation [911]. The investigation focused on the stall modes, identifying a rotating stall inception mechanism driven by circumferentially localised pressure disturbances confined to the blade passage's tip region. Localisation of the disturbances in the blade tip region supports the hypothesis of a causal link between tip clearance flow and stall inception.

Some scholars have focused on the physics underlying the tip clearance flow related mechanisms that can lead to the formation of pressure disturbances. Among them, Koch and Smith [12] and Saathoff and Stark [13] have observed experimentally that a fan reaches the limit of its pressure developing capability when the interface between the incoming flow and tip clearance vortex region linedup with the leading edge plane at the blade tip. Numerical simulation has revealed two more mechanisms related to the onset of tip blockage growth $[14,15]$, namely: (i) the backflow of tip clearance fluid at the trailing edge impinging on the blade pressure side of adjacent blades and (ii) the spillage of tip clearance fluid ahead of the blade leading edge below the blade tip into the next blade passage.

Scholars who have studied aerodynamic instability in fans, and compressors have suggested that some features of the tip flow of both are directly responsible for the generation of short wavelength disturbances (also called "spikes" or "pips") that cause the inception of localised part-span stall cells [16-18].

\section{Historical Overview of Antistall Concepts}

Given the potentially catastrophic consequences of a stall event, there is an incentive for developing technologies that can extend the stable operating range of axially decelerating turbomachinery without undue performance degradation. Previously, Hathaway [19] systematically reviewed techniques and design concepts to improve the stall-free operating margin or to suppress a stall event.

Hathaway noted the earliest proposed techniques from the 1950s that had successfully extended the axial compressor's stable operating range: Wilde [20], on behalf of RollsRoyce Ltd, and Turner [21] on behalf of Power Jets Ltd, filed patents. These concepts were both based on the treatment of the casing end-walls motivated by a desire to control the boundary layer development by combining rear air bleeding and front reinjection [20] or the use of holes and slots as a method of promoting turbulence, and in so doing, energising the end-wall flow [21].

Griffin and Smith [22] conducted the first systematic experimental campaign on so-called "porous end-walls" in compressor rotors during the 1960s at NASA. Their work demonstrated improved stall margins in cascade tunnels irrespective to the air blowing/bleeding. In a similar vein, scholars studied casing treatments, specifically holes, slots, and grooves with and without plena in the 1970s [2325 ]. They found their effectiveness primarily associated with delaying the onset of stall in tip-limited blade rows.

Takata and Tsukuda [26] conducted detailed measurements within casing slots and found that they achieved their antistall effect as a consequence of periodic pumping of the flow within the slots into the main stream. Moreover, Greitzer et al.'s [27] investigations demonstrated that the end-wall treatments were effective mostly in high-solidity 


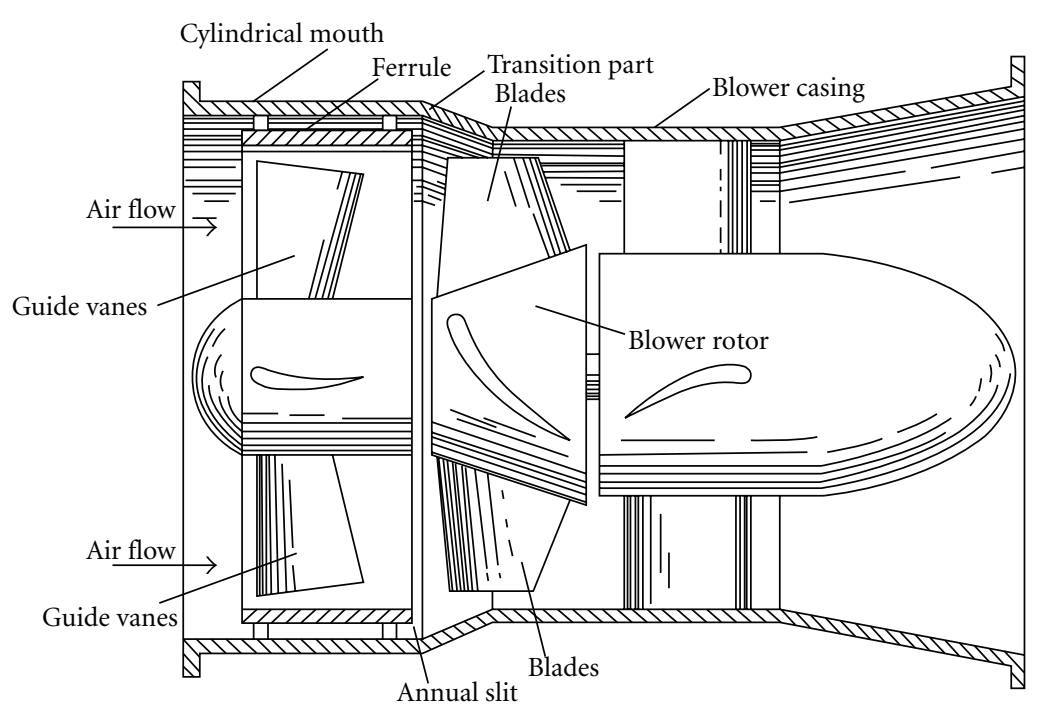

FIGURE 1: The proposed "blower arrangement" [2].

blade rows prone to wall stall, but not in low-solidity rotor affected by blade stall.

In the 1990s, researchers proposed concepts to exploit the potential benefits of flow bleeding (from the stalled region) and blowing (into the clean inflow), and in so doing, revisited earlier stall inception concepts. Most notably, Koff et al. [28], Khalid [29], Nolcheff [30], and Gelmedov et al. [31] patented different variants of recirculating casing treatment. A common theme with the different recirculating casing treatments was the provision of a path through the casing for low momentum fluid recirculating upstream from the blade tip leading edge.

More recently, Hathaway [19] observed that the most significant advances in antistall devices have resulted as a consequence of insight into the flow mechanism that researchers associate with three specific technologies: first, circumferential grooves; second, tip injection control technology; third, stage recirculation devices. Fan and blower designers most favour the stage recirculation devices.

\section{Passive Control by Stabilisation Rings}

Since the early 1960s, scholars have endeavoured to develop stage recirculation devices tailored to the pressure rise and volume flow rate ranges typical of industrial fans. Ivanov [2] received the first patent. The concept is of an annular "slit" in the casing upstream of the blades (Figure 1) that stabilises fan performance as it approaches stall.

The slit enabled air to recirculate through the slit formed between the cylindrical mouth and ferrule, Figure 1. A set of guide vanes then redirected the recirculating flow in an axial direction as it turns back and reenters the fan blades. As the fan approaches stall, the slit and static vanes provide a path for low momentum flow to recirculate. In practice, this stabilises fan performance.

Karlsson and Holmkvist [32] filed a patent application on 15 March 1984, developing and enhancing Ivanov's [2] patent by incorporating static vanes into the casing. Then, Bard [33] named the vanes embedded within the fan casing a "stabilisation ring." Miyake and Inaba [34] further developed and patented the original concept proposing the use of airseparators based on an open circumferential cavity facing the rotor-blade tips, which Yamaguchi et al. [35] further developed. Similarly, Kang et al. [36] optimised casing recess geometries and their relative position to the blade rows.

Despite subsequent developments to the concept, the fan community has mostly adopted Karlsson and Holmkvist's [32] configuration. In practice, the concept has proven highly effective as with the stabilisation ring guide, vanes remove the momentum component both radially and circumferentially and reinject the flow in the axial direction. The flow through the stabilisation ring vanes is turned such that it exits the vanes upstream from the impeller, reenergised, and flowing in an axial direction.

The effect of the stabilisation ring on the fan characteristic is to eliminate the sharp drop in its pressure developing capability, which engineers classically associate with fan stall. The primary characteristic of a tunnel ventilation fan fitted with a stabilisation ring is continuously rising pressure back to zero flow. It was this modification in the fan characteristic that led to tunnel ventilation fan designers widely embracing the use of stabilisation rings.

A continuously rising characteristic facilitates multiple fan operation in parallel. As a fan speed falls, its pressure developing capability also falls. During a fan's starting and stopping transient, its pressure developing capability will be below what other fans generate when operating in parallel. As a consequence, a fan in parallel operation will inevitably drive transiently into stall each time it starts or stops. During the 1980s, variable speed drives were not widely available. Therefore, varying the speed of all fans in a parallel installation was not practical, making it inevitable that individual fans would have to start and stop, whilst others ran at full speed. 
The ability of the stabilisation ring to facilitate the starting and stopping of individual fans when in parallel operation was critically important. Application of the stabilisation ring largely eliminated inservice mechanical failure in tunnel ventilation fan parallel operation.

A particular feature of the environment within which tunnel ventilation fans operate is the pressure pulses associated with the movement of a train through a tunnel. Pressure pulses can be up to $\pm 50 \%$ of the overall work coefficient. Such pressure pulses drive the fan first up and then down its characteristic operating range, Figure 2. To ensure that the tunnel ventilation fan continues to operate in an aerodynamically stable manner during this pressure transient, aerodynamic design of the fan requires the incorporation of sufficient margin to ensure that the fan does not stall due to high positive or negative inlet flow angle.

This propensity to stall under large pressure fluctuations is complicated in offdesign conditions when a tunnel ventilation fan operates at partial speeds. When a fan operates at reduced speed, its flow and pressure-developing capability also reduces. Because the pressure pulse of a passing train remains constant, there will be a critical speed when the fan is close to stall, but has not actually stalled. Below that critical speed, the fan stalls in positive incidence as the train approaches and then stalls in negative incidence as the train departs, Figure 2. This combination of positive-incidence aerodynamic stall and negative-incidence aerodynamic stall causes a significant increase in the unsteady forces applied to the fan blades.

\section{Technology Description}

In order to establish the likelihood of mechanical failure of tunnel ventilation fans in applications where aerodynamic stall is likely due to the presence of pressure pulses, the researchers selected a fan typical of tunnel ventilation applications as Table 1 below illustrates.

The chosen fan was from a family of tunnel ventilation fans. Although each fan within the family is physically different, all are designed using the same mechanical design methodology. The researchers chose the fan configurations for experimental testing as a consequence of the application into which manufacturers supply tunnel ventilation fans. Tunnel ventilation fans are typically subjected to pressure pulses. Therefore, the researchers tested the fan

(i) with a stalling blade angle, without a fitted stabilisation ring at design speed;

(ii) with a stalling blade angle, with a fitted stabilisation ring at design speed;

(iii) with a nonstalling blade angle and no stabilisation ring at design speed;

(iv) with a stalling blade angle and no stabilisation ring at $50 \%$ design speed;

(v) with a stalling blade angle and no stabilisation ring at $25 \%$ design speed.

The researchers installed the fan in a ducted test system. They measured the fan performance according to the

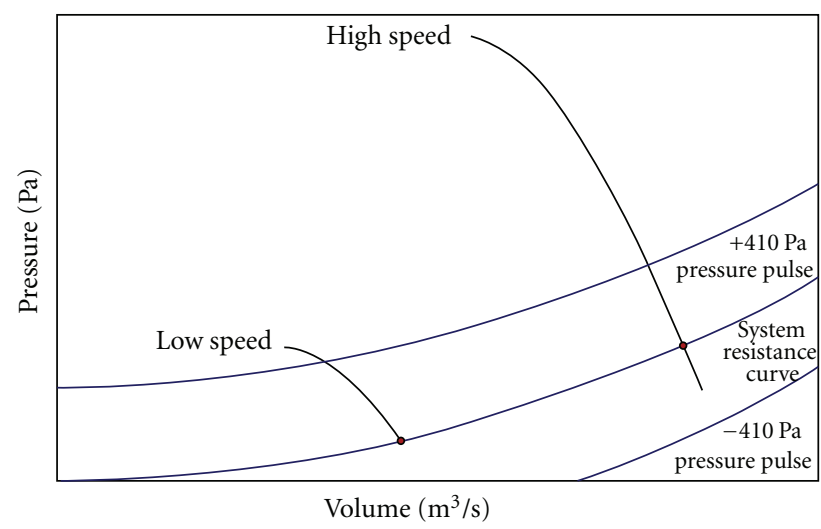

FIGURE 2: Fan performance under a pressure pulse at full and part speed.

Table 1: Fan data.

\begin{tabular}{lc}
\hline Nominal speed & $980 \mathrm{rpm}$ \\
Tip speed & $115 \mathrm{~m} / \mathrm{s}$ \\
Nominal pressure coefficient, $\Psi_{\text {nom }}$ & 0.189 \\
Nominal flow coefficient, $\Phi_{\text {nom }}$ & 0.220 \\
Duty point efficiency, $\eta_{\text {tot }}$ & 0.69 \\
Tip diameter & $2,240 \mathrm{~mm}$ \\
Blade height & $720 \mathrm{~mm}$ \\
Blade chord at the tip & $163 \mathrm{~mm}$ \\
Tip stagger angle & $70^{\circ}$ \\
Tip gap ( $\%$ of fan diameter) & $0.45 \%$ \\
Blade count & 16 \\
Tip solidity & 0.37 \\
\hline
\end{tabular}

International Standard ISO 5801:2007 (2007). By throttling flow downstream from the fan rotor, the researchers induced aerodynamic instabilities of interest. During the flow/pressure throttling, the fan remained in rotating stall without going into surge, irrespective of the rotor speed. The rotor aerodynamic load and the plenum geometry ensured that the system could not develop a counter-pressure high enough to induce a surge.

The researchers developed a solid model of the test fan's blade using a CAD package, and they used a finite element analysis programme for structural analysis. They applied centrifugal force and bending moments (due to the design radial work distribution) using Sheard et al.'s [37] original method using nodal forces in the finite element analysis boundary conditions in order to calculate blade stress. The authors applied strain gauges to three blades in the three locations that they predicted as the blades' highstress regions.

Stain gauges were applied using the method of Boyes (2003:77). After chemical cleaning of the blades to be instrumented, foil gauges were applied. Foil gauges were chosen as their flatness makes adhesion easier and improves heat dissipation. The instrumentation system utilised was an adaption of that originally developed by Wasserbauer et al. [38] who reported the design of a low-speed axial compressor 
test facility at what was then named NASA Lewis. Strain gauge leads are routed from the rotating to static frame of reference though a four-channel electrical slip ring to a set of strain gauge amplifiers. The output of the strain gauge amplifiers was then logged using a PC-based data acquisition system running the software package LabView.

\section{Experimental Results}

Application of multiple strain gauges to separate blades enabled the authors to experimentally determine the actual highest stress location, as well as the impact of manufacturing tolerances from blade to blade. The variation in strain gauge output from blade to blade at nominally the same location on different blades was $2-3 \%$. This variation constitutes a combination of errors associated with gauge calibration, uncertainty in gauge location, and blade-toblade variation of blade geometry.

Using data from a typical strain gauge located at the highest stress position on one blade, the researchers established fan performance with and without a fitted stabilisation ring as Figure 3 illustrates. When throttling the fan without a fitted stabilisation ring, pressure rises until it reaches a peak and then falls as the fan stalls. This is the classical fan characteristic. In the study, the blade's peak alternating stress increased from 2.27 MPa (Point A, Figure 3) to $3.53 \mathrm{MPa}$ as the researchers throttled the fan. As the fan stalled, peak alternating stress increased to 16.00 MPa (Point B, Figure 3).

When the researchers throttled the fan with a stabilisation ring, pressure rose continuously with no evidence of a reduction in pressure developing capability as the fan passed through the point at which it stalled without a stabilisation ring, Figure 3. The fan characteristic is remarkable in that the pressure rises so smoothly that it is barely possible to identify the onset of stall from the fan's flow/pressure characteristic. However, in studying the strain gauge data, it is apparent that the initial alternating stress level is $2.13 \mathrm{MPa}$ (Point C, Figure 3) and remains lower than a fan without a stabilisation ring until the onset of stall. As the fan fitted with a stabilisation ring approaches stall, there is a single point (at $60 \mathrm{~m}^{3} / \mathrm{s}$ ) where the data from the fan without a stabilisation ring measures lower stress than the fan with a stabilisation ring. Alternating stress in the fan with a stabilisation ring goes on to peak at 4.60 MPa (Point D, Figure 3).

Using data from a typical strain gauge located at the highest stress position on one blade, the researchers established fan performance with a nonstalling blade angle and no fitted stabilisation ring. The researchers compared data with data for a stalling blade angle with a fitted stabilisation ring as Figure 4 illustrates. The authors compared the two data sets as a nonstalling blade angle without a stabilisation ring or stalling blade angle with the stabilisation ring representing the two available choices to tunnel system designers who wish to specify a "stall tolerant fan."

The change in blade angle from stalling to a nonstalling reduces the fan pressure developing capability by approximately $25 \%$, Figure 4 . The researchers tested the fan with the stalling blade angle and fitted stabilisation ring under stable and stalled aerodynamic conditions. The alternating stress

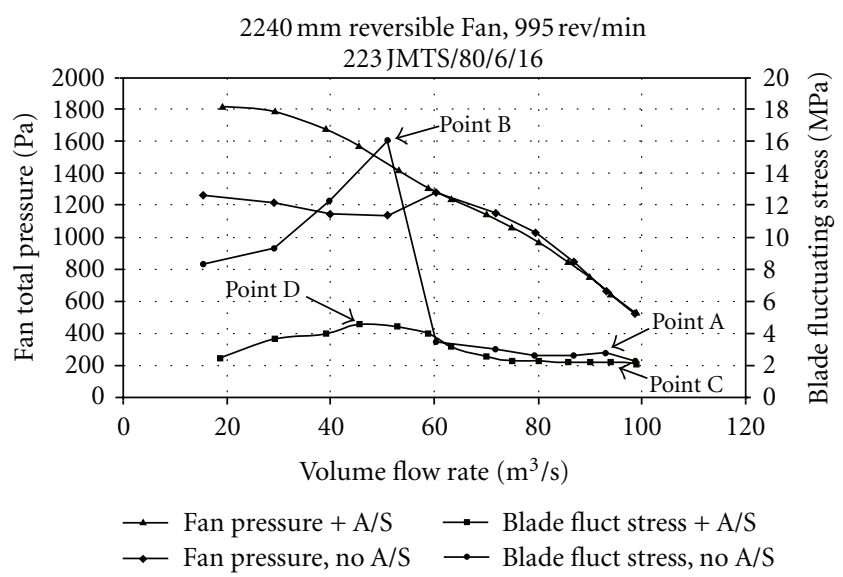

FIGURE 3: Stall characteristics of the test fan with and without a fitted stabilisation ring.

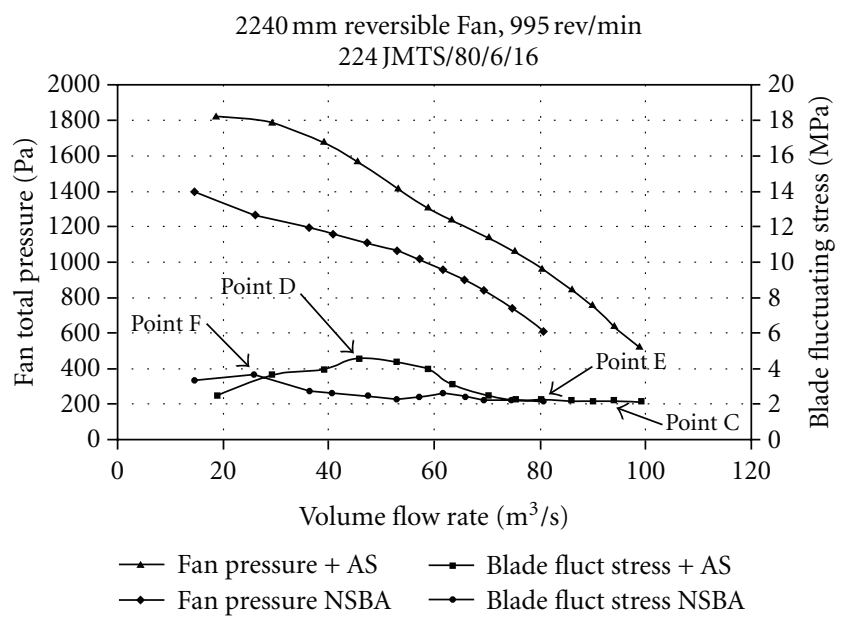

FIGURE 4: Stall characteristics of the test fan with a nonstalling blade stagger angle.

increased from the initial alternating stress level of $2.13 \mathrm{MPa}$ (Point C, Figure 4), going on to peak at $4.60 \mathrm{MPa}$ (Point D, Figure 4). In contrast, a nonstalling blade angle without a stabilisation ring, increased from an initial 2.19 MPa (Point E, Figure 4), going on to peak at 3.68 MPa (Point F, Figure 4).

The peak alternating stress with the nonstalling blade angle and no fitted stabilisation ring was 20\% lower than a stalling blade angle and fitted stabilisation ring. The researchers considered the uncertainty of the measurement approximately $2 \%$, and consequently, a $20 \%$ reduction in peak alternating stress is an order of magnitude greater than the uncertainty of the measurement. The above result indicates that a fan with a nonstalling blade angle and no fitted stabilisation ring will be subject to lower peak alternating stress during aerodynamic stall than the same fan with stalling blade angle and a fitted stabilisation ring.

Using data from a typical strain gauge located at the highest stress position on one blade, the researchers established fan performance with a stalling blade angle, and no stabilisation rig fitted at $100 \%, 50 \%$, and $25 \%$ design 
speed. The availability of variable speed drives has resulted in tunnel ventilation fans routinely operating at part speed. The researchers compared the data at $100 \%$ speed with data at $50 \%$ speed, as Figure 5 illustrates. The authors compared the two data sets, as tunnel ventilation fans selected to not stall in the presence of a pressure pulse at $100 \%$ speed, routinely stall in the presence of the same pressure pulse at $50 \%$ speed.

The same alternating stress data for a fan with stalling blade angle and no fitted stabilisation ring is plotted, with alternating stress increasing from the initial alternating stress level of $2.27 \mathrm{MPa}$ (Point A, Figure 5), going on to peak at 16.00 MPa (Point B, Figure 5). In contrast, the same fan running at $50 \%$ speed had an initial alternating stress of $0.57 \mathrm{MPa}$ (Point G, Figure 5), going on to peak at $4.00 \mathrm{MPa}$ (Point H, Figure 5). As this paper previously mentioned, at full speed, the alternating stress increased to $3.53 \mathrm{MPa}$ immediately prior to aerodynamic stall. As such a fan running at a speed of $100 \%$ (with no aerodynamic stall in the event that a pressure pulse) would see a maximum alternating stress of $3.53 \mathrm{MPa}$. The same fan running at $50 \%$ speed has a reduced pressure developing capability and so would in all probability stall in the presence of the same pressure pulse, and in doing so, be exposed to a peak alternating stress of 4.00 MPa.

In some metro tunnel ventilation systems, it is customary to operate tunnel ventilation fans at $25 \%$ design speed. The same alternating stress data for a fan with stalling blade angle and no fitted stabilisation ring is plotted for the fan running at $50 \%$ speed, with alternating stress increasing from the initial alternating stress level of $0.57 \mathrm{MPa}$ (Point $\mathrm{G}$, Figure 6), going on to peak at 4.00 MPa (Point H, Figure 6). In contrast, the same fan running at $25 \%$ speed had an initial alternating stress of $0.14 \mathrm{MPa}$ (Point I, Figure 6), going on to peak at $1.00 \mathrm{MPa}$ (Point J, Figure 6). The alternating stress level during aerodynamic stall at $25 \%$ speed $(1.00 \mathrm{MPa})$ is significantly lower than the alternating stress level during stable operation at $100 \%$ speed $(3.53 \mathrm{MPa})$ and, therefore, the researchers concluded that it posed no risk to the fan's mechanical integrity.

\section{Structural Analysis}

The term "fatigue" refers to the phenomenon whereby virtually all materials will break under numerous stress repetitions that are not sufficient to produce an immediate rupture in the first instance. In this regard, fan blades are subject to fatigue stress induced by (i) the mean force arising from rotation and aerodynamic loading and (ii) the alternating force produced by variations in lift as the fan rotates. The combination of mean and alternating blade forces result in mean and alternating blade stress. This makes the blades inherently susceptible to fatigue.

The endurance limit corresponding to any given range of stress variation has been the subject of extensive study, reviewed by amongst others Young [39], as has the ability of a wide range of materials to withstand different combinations of mean and alternating stress. Manufacturers usually produce tunnel ventilation fan blades from aluminium and the ability of aluminium to resist fatigue for a fixed alternating

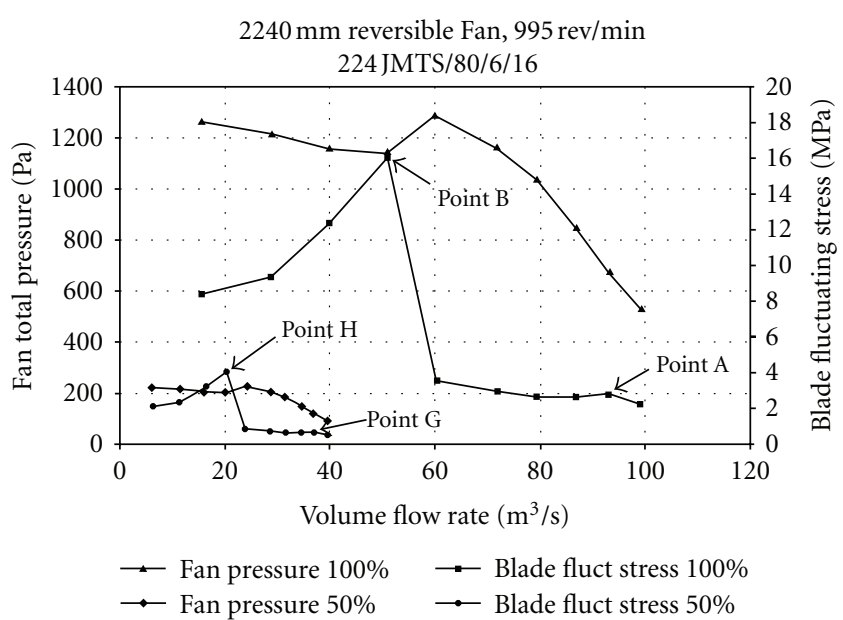

Figure 5: Stall characteristics of the test fan with a stalling blade stagger angle at full and half speed.

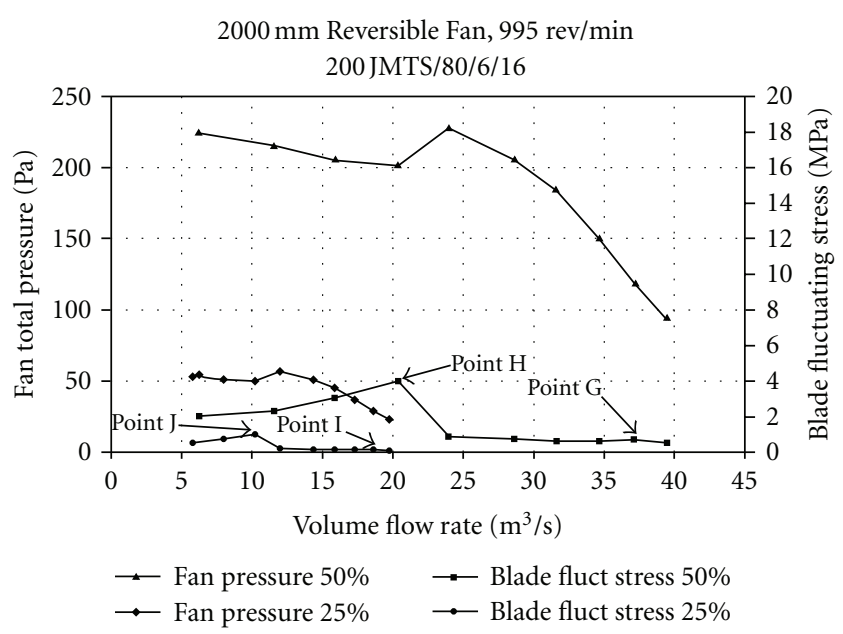

FIGURE 6: Stall characteristics of the test fan with a stalling blade stagger angle at half and quarter speed.

stress reduces as mean stress increases. When researchers study material test data for various levels of mean and alternating stress, they derive a relationship known as the Gerber Line, Figure 7.

Gerber [40] himself derived this line and proposed a parabolic relationship between alternating stress and mean stress in iron structures. The maximum alternating stress level $\sigma$ for any mean stress in the material, up to the tensile strength of the material, is given by the expression:

$$
\pm \sigma= \pm \sigma_{0}\left\{1-\left(\frac{\sigma_{m}}{\sigma_{t}}\right)^{2}\right\} .
$$

$\sigma_{0}$ is the alternating stress level that constitutes the fatigue limit of the material with zero mean stress. $\sigma_{t}$ is the tensile strength of the material. $\sigma_{m}$ is the mean stress in the material.

The ability of a given aluminium alloy to resist the effect of mean and alternating stress is dependent on the maximum defect size in the material samples. The larger 


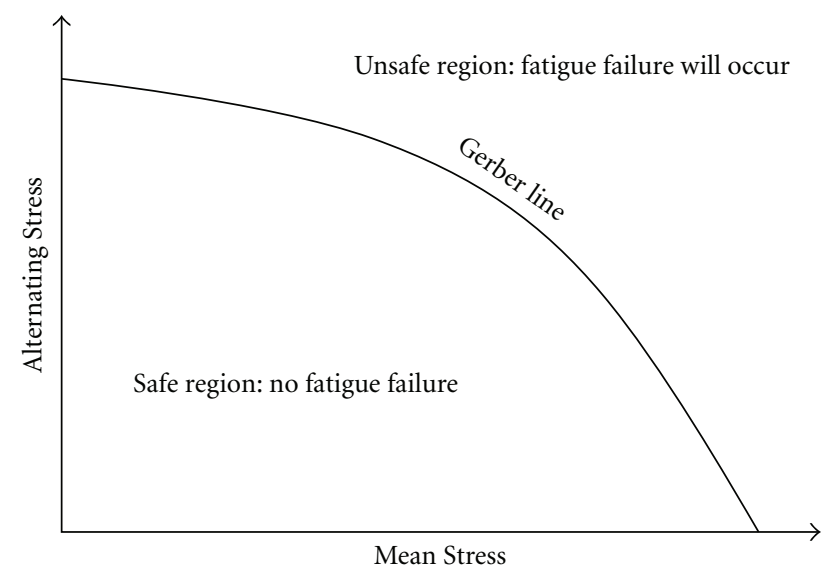

Figure 7: The curve of best fit through material test data is the Gerber Line.

the defect, the lower the level of mean and alternating stress required to induce fatigue failure. Tunnel ventilation fans manufacturers, therefore, first experimentally establishes the relationship between mean and alternating stress for a given defect size, and then undertakes X-ray examination of all rotating components to ensure that the maximum defect size is below that on which they established the Gerber Line.

If the peak mean/alternating stress point is below the Gerber Line, the fan blade should not fail due to fatigue. However, in practice, there is some uncertainty about the location of all Gerber Lines as they are derived from experimental data. Additionally, the ability to calculate mean and alternating stress levels is imperfect as a consequence of assumptions during the modelling process. Therefore, in practice, tunnel ventilation fan designers classically choose to design fans with a safety factor of two. In this context, we define a safety factor of two as an alternating stress half that of the Gerber line at a given value of direct stress.

The authors assessed the significance of the measured alternating stress results. The manufacturers designed the family of fans that the authors used in the reported research with direct and alternating stress levels that would fall on a Gerber Line calculated with a safety factor of two. The authors combined predicted direct and measured alternating stress levels for the fan operating on a stable part of its characteristic, with no fitted stabilisation ring and a stalling blade angle to give a safety factor of 2.3, Table 2 . The experimentally derived safety factor was greater than two, giving confidence in the conservative nature of the manufacturers mechanical design methodology.

Throttling the fan until stall without a stabilisation ring resulted in increasing alternating stress. The resultant combination of direct and alternating stress is significantly beyond the Gerber Line, giving a safety factor of 0.3 (Table 2 ). From this, we may conclude that if this fan operated in the stalled condition for an extended period of time, it would suffer a fatigue-related failure.

The researchers measured direct and alternating stress levels during stable and stall conditions for the test fan with stalling blade angle and a fitted stabilisation ring, Table 2.
The reduction in alternating stress during stable operation resulted in the fan operating with a slightly higher safety factor of 2.5. In stalled operation, the alternating stress increased and, in so doing, reduced the safety factor to 1.1. As a safety factor of 1.1 is greater than one, the mechanical design of the tested fan can tolerate the increase in alternating stress. However, the uncertainty of the Gerber Line location is significant enough for a conservative tunnel ventilation fan designer to consider it low.

The researchers measured direct and alternating stress levels during normal and stall conditions for the test fan with a nonstalling blade angle and no stabilisation ring, Table 2. The increase in alternating stress compared to the same fan with stalling blade angle and a fitted stabilisation ring during stable operation resulted in the fan operating with a slightly lower safety factor of 2.4. In stalled operation, the alternating stress increased and, in so doing, reduced the safety factor to 1.5. As a safety factor of 1.5 is greater than one, the mechanical design of the tested fan can tolerate the increase in alternating stress, and therefore, the risk of a fatigueinduced mechanical fan failure is low.

Operating the fan at $100 \%, 50 \%$, and $25 \%$ speed in both stable and stalled operation facilitated in the calculation of six safety factors, Table 3 . This study reports a tunnel ventilation fan safety factor during stable operation at $100 \%$ speed of 2.3 ( 0.3 higher than the desirable minimum). In a stalled condition, we reduced the safety factor to 0.3 , which is significantly lower than 1.0. This indicates that if the fan continued to operate in stall at $100 \%$ speed, the blades would suffer fatigue failure.

During normal operation, safety increased from 2.3 at $100 \%$ speed to 10.0 at $50 \%$ speed, a factor of approximately four. Mean stress in a fan blade reduces with the square of speed, therefore reducing speed by half than expected, thus increasing the safety factor by four. When the authors operated the fan at $50 \%$ speed during stalled operation, the safety factor was 2.5 , Table 3 (an increase of more than six compared to the same fan operating in stall at $100 \%$ speed). The increase in the safety factor is a consequence of the aerodynamically induced alternating stresses (when operating the fan in stall) falling more rapidly then the mean stress falls when the authors reduced fan speed from $100 \%$ to $50 \%$.

The safety factor at $50 \%$ speed when operating in stall (2.5) was slightly higher than the safety factor at $100 \%$ speed in stable operation (2.3). As the safety factor at 50\% when operating in stall is higher then the safety factor of the same fan at $100 \%$ speed in stable operation, the authors observed that the fan was less likely to fail mechanically at 50\% speed then when at $100 \%$ speed in stable operation.

The above result is significant because tunnel ventilation fans in metro applications routinely operate at both $50 \%$ and $25 \%$ speeds. As a consequence of the reduced pressuredeveloping capability of the fans at reduced speed, fans in metro applications are routinely driven into stall. The calculated safety factors at $25 \%$ design speed are so high during both stable and stalled operation that we can conclude that aerodynamic stall poses no threat to the mechanical integrity of the tunnel ventilation fan. 
TABLE 2: Safety factor derived from strain gauge data for a fan at full speed with and without a fitted stabilisation ring.

\begin{tabular}{lccc}
\hline Fan type & \% Full speed & Normal operation safety factor & Stalled operation safety factor \\
\hline Plane casing, stalling blade angle & 100 & 2.3 & 0.3 \\
Antistall casing, stalling blade angle & 100 & 2.5 & 1.1 \\
Plane casing, nonstalling blade angle & 100 & 2.4 & 1.5 \\
\hline
\end{tabular}

TABle 3: Safety factor derived from strain gauge data for a fan at full and part speed without a fitted stabilisation ring.

\begin{tabular}{lccc}
\hline Fan type & \% Full speed & Normal operation safety factor & Stalled operation safety factor \\
\hline Plane casing, stalling blade angle & 100 & 2.3 & 0.3 \\
Plane casing, stalling blade angle & 50 & 10.0 & 2.5 \\
Plane casing, stalling blade angle & 25 & 106.0 & 7.3 \\
\hline
\end{tabular}

The above results indicate that the tested fan may operate at $100 \%$ speed in the stable part of its characteristic, with a mechanical safety factor of 2.3. The same fan can operate also at $50 \%$ speed in aerodynamic stall with a mechanical safety factor of 2.5. When the authors scale the fan characteristic to $90 \%$ speed, the pressure-developing capability reduced to the point where a $500 \mathrm{~Pa}$ pressure pulse would take the fan within $5 \%$ of the fan's peak pressure-developing capability.

Next, the authors scaled the direct stress from 50\% to $55 \%$ design speed and recalculated the associated mechanical safety factor with operation in an aerodynamically stalled condition. The mechanical safety factor reduced from 2.5 at $50 \%$ design speed to 2.0 at $55 \%$ design speed. From the above, the authors concluded that the tested fan could operate at up to $55 \%$ design speed in aerodynamic stall and down to $90 \%$ design speed without stalling. As such, the authors observed that if they fitted this particular fan with a variable speed drive (VFD), the "forbidden" speed range should be 55-90\% speed for the tested design point, assuming a $500 \mathrm{~Pa}$ pressure pulse.

\section{Strategy for Fan Selection}

The demand for new mass-transit systems generally, and metro systems in urban areas specifically, has increased rapidly over the last two decades and continues today. However, recent changes in market requirements for tunnel ventilation fans present fan designers with a challenge. The proposed tunnels for the next generation of mass transit systems are longer than the historic norm, and the trains that run in them are to run faster. These two factors result in mass-transit systems requiring higher pressure ventilation fans (as the tunnels are longer) with the capability of operating under the influence of larger pressure pulses (as the trains are running faster).

An additional factor increasing the magnitude of pressure pulses in metro systems is the trend towards the use of platform screen doors. Platform screen doors at metro stations screen the platform from the train. They are a relatively new addition to metro systems and are today in wide use in Asia and Europe. Passenger safety is driving the adoption of platform screen doors. By separating the platform from the train, platform screen doors prevent the travelling public either accidentally or deliberately falling into the path of oncoming trains. Additionally, metros designed to use driver-less trains are only considered safe if platform screen doors are included in the design. Consequentially, it is likely that an increasing proportion of new and refurbished metro stations will include platform screen doors.

Historically, a pressure of 1,200 Pa with pressure pulses of typically $300 \mathrm{~Pa}$ has been typical in tunnel ventilation system application. Today, a pressure of $1,500 \mathrm{~Pa}$ with pressure pulses of $500 \mathrm{~Pa}$ is typical. Increasing pressure and pressure pulse size increase the importance of tunnel ventilation fan selections that either avoid or manage the effect of fan stall.

A modern mass transit system in a busy urban area can have 500 trains a day passing each tunnel ventilation shaft. Consequently, the fans in those ventilation shafts are subjected to 500 pressure pulses a day and therefore, are potentially driven into stall each time. With a typical inservice life of 20 years, the probability of incorrectly selected fans for the application suffering a fatigue-induced mechanical failure becomes high.

Tunnel ventilation fan designers have classically utilised one of three approaches during the selection of tunnel ventilation fans that must operate in the presence of pressure pulses.

(i) Select a fan with a nonstalling blade angle, such that as the fan is driven out of its normal operating range, mechanical stress increases within manageable limits.

(ii) Select a fan with a high enough pressure-developing capability to operate with a pressure pulse without stalling.

(iii) Select a fan with a stabilisation ring, such that as the fan is driven out of its normal operating range, mechanical stress increases within the limit of the mechanical design.

All three fan selection strategies are valid, and tunnel ventilation system designers have used each for tunnel ventilation system design. The first strategy, a fan with a nonstalling blade angle is the most conservative selection strategy. One may select the fan close to its optimum operating point, without having to compromise the selection to accommodate a pressure pulse within the stable operating range. 
TABLE 4: Factors impacting on fan capital and through life cost.

\begin{tabular}{lc}
\hline Design point pressure & $1.500 \mathrm{~Pa}$ \\
Pressure pulse & $500 \mathrm{~Pa}$ \\
Design point flow & $85 \mathrm{~m}^{3} / \mathrm{s}$ \\
Fan type & Reversible, $300^{\circ} \mathrm{C}$ for 2 hours \\
Running hours per year & $4.400(12$ hours a day $)$ \\
Cost of electricity & $0.04 \mathfrak{E}$ per $\mathrm{kW} /$ Hour \\
Cost of capital & $8 \%$ \\
Period of assessment & 10 years \\
\hline
\end{tabular}

The second strategy, a fan with a high enough pressuredeveloping capability to operate with a pressure pulse without stalling, works well with smaller pressure pulses. However, as the size of the pressure pulse increases, the fan's operating point moves further from the optimum resulting in a less efficient fan selection. Despite the reservation about fan efficiency, this strategy avoids the fan stalling completely in the event of foreseen events. Tunnel ventilation system designers who are confident in their ability to predict the conditions under which the fans will operate during all tunnel ventilation system scenarios favour this second strategy.

The third strategy, a fan with a fitted stabilisation ring, works well with larger pressure pulses, allowing fan selection close to its peak aerodynamic efficiency and then effectively managing the mechanical consequences of driving into stall under the influence of pressure pulses. Tunnel ventilation system designers who favour this strategy argue that it is not possible to guarantee that the fan will never drive into stall; therefore, a stabilisation ring that provides mechanical protection in the event of aerodynamic stall is prudent. The tunnel ventilation system designers who favour this approach cite the possibility that occasionally two trains might pass close to a ventilation shaft, effectively doubling the size of the pressure pulse.

To facilitate comparison of the three strategies, the authors have made assumptions typical of a present day urban area metro system as Table 4 illustrates.

When considering the required pressure, flow and size of the pressure pulse, the first strategy, a fan with a nonstalling blade stagger angle, results in a fan of 2.50 metre diameter with a design point efficiency of $71 \%$ (see Figure 8 ). The second strategy, a fan that can accommodate the pressure pulse, results in a fan of 1.80 metre diameter with a design point efficiency of $66 \%$ (see Figure 9). The third strategy, use of a stabilisation ring, results in a fan of 2.24 metre diameter with a design point efficiency of $69 \%$ (see Figure 10).

We can combine the capital cost of each fan selection strategy with the Table 4 assumptions to calculate throughlife cost of each strategy (See Table 5). We define the initial capital cost in Table 5 as the initial cost of purchasing and installing the ventilation fan. Table 5 defines operating cost as the cost of fan purchase and installation plus electricity costs over ten years, based on Table 4 assumptions. To facilitate a direct comparison between initial capital cost and operating cost, Table 5 presents the net present value of operating costs.

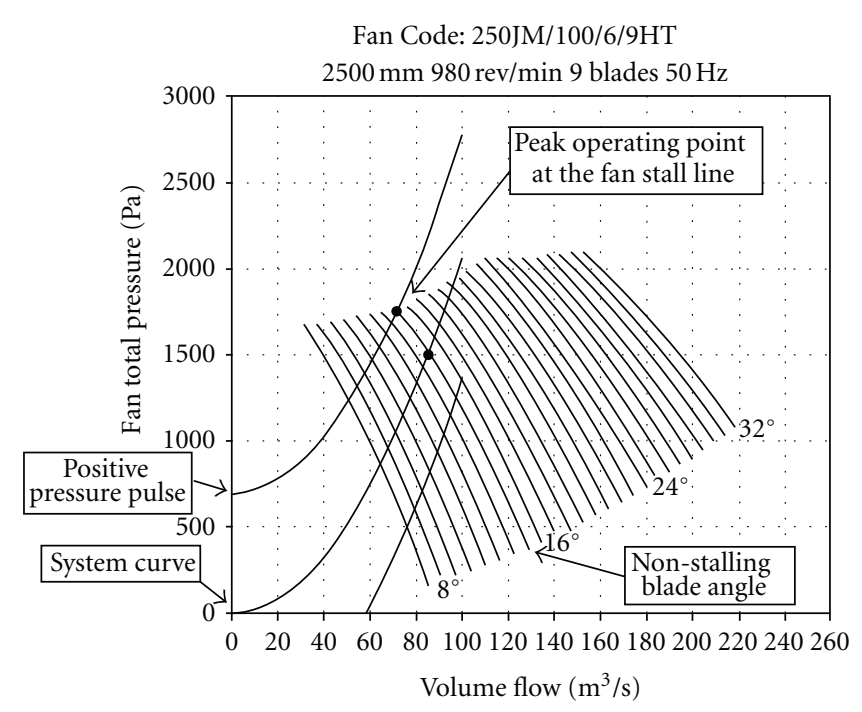

FIGURE 8: Optimum fan selections for a common duty point, fan selection strategy one: nonstalling blade stagger angle.

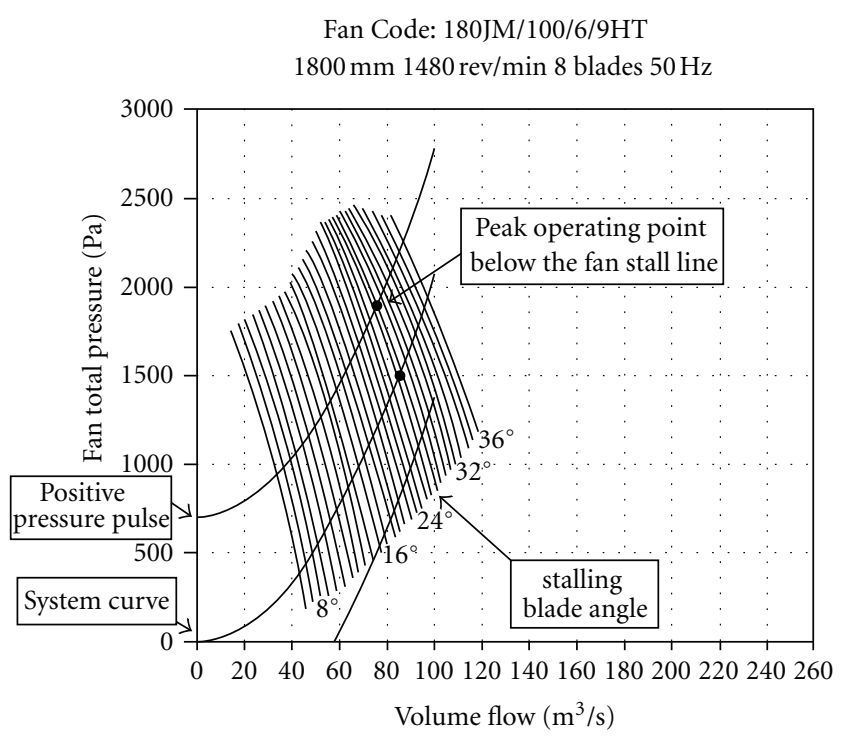

FIGURE 9: Optimum fan selections for a common duty point, fan selection strategy two: high-pressure capability.

As previously mentioned, different tunnel ventilation system designers favour different fan selection strategies. However, all three strategies have reliable inservice records. In this example, the largest fan (Strategy One) has the lowest operating cost over ten years, Table 5, despite not having the highest initial cost, making this selection strategy attractive to those seeking the lowest cost of ownership.

In this example, the smallest fan (Strategy Two) has the highest operating cost over ten years, Table 5, despite having the lowest initial cost, making this selection strategy apparently unattractive to those seeking lowest cost of ownership. However, if one accounts for the cost of excavating an underground plant room, the cost of building a plant room for a 2.5 metre diameter fan (Strategy One) may be 
TABle 5: Capital cost and ten year though life cost of each selection strategy.

\begin{tabular}{|c|c|c|c|c|c|c|c|c|}
\hline & $\begin{array}{c}\text { Fan } \\
\text { diameter } \\
(\mathrm{m})\end{array}$ & $\begin{array}{c}\text { Fan } \\
\text { efficiency }\end{array}$ & $\begin{array}{c}\text { Fan } \\
\text { investment } \\
\text { cost }(\mathfrak{E})\end{array}$ & $\begin{array}{c}\text { Motor } \\
\text { power } \\
(\mathrm{kW})\end{array}$ & $\begin{array}{c}\text { Electricity } \\
\text { cost/year }(\mathfrak{E})\end{array}$ & $\begin{array}{l}\text { Electricity cost } \\
\quad(10 \mathrm{yrs})(\mathfrak{E})\end{array}$ & $\begin{array}{c}\text { Total fan and } \\
\text { running costs }(\mathfrak{E})\end{array}$ & $\begin{array}{c}\text { Running cost as a } \\
\text { percentage of } \\
\text { total cost }\end{array}$ \\
\hline Strategy 1 & 2.5 & $71 \%$ & 28.500 & 185 & 32.412 & 217.488 & 245.988 & $88 \%$ \\
\hline Strategy 2 & 1.8 & $66 \%$ & 23.000 & 214 & 37.493 & 251.582 & 274.982 & $92 \%$ \\
\hline Strategy 3 & 2.24 & $69 \%$ & 32.000 & 190 & 33.288 & 223.366 & 255.366 & $87 \%$ \\
\hline
\end{tabular}

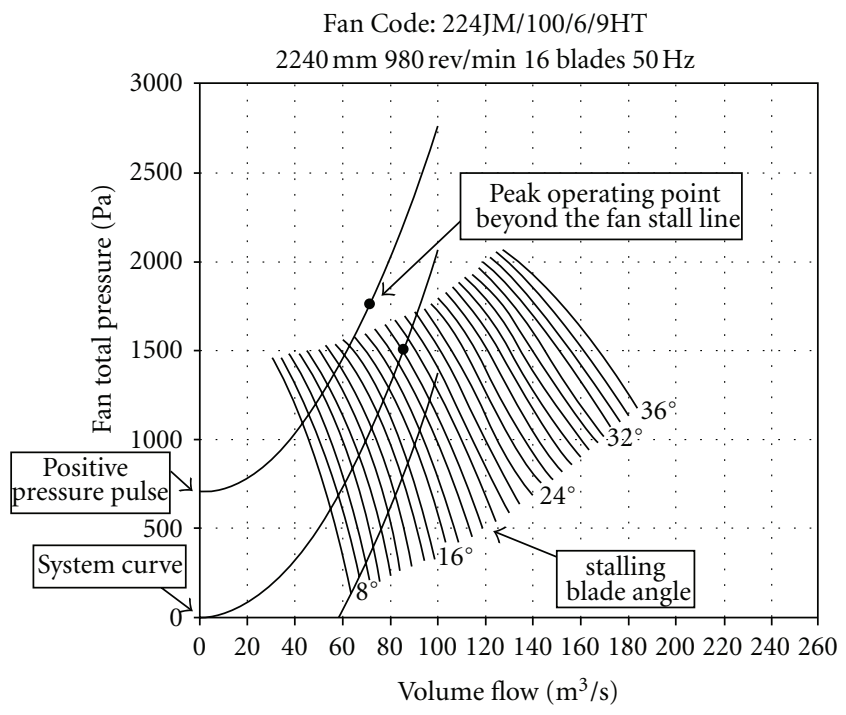

Figure 10: Optimum fan selections for a common duty point, fan selection strategy three: stabilisation ring.

significantly higher than the cost of building a plant room for a 1.8-metre-diameter fan (Strategy Two), therefore making the second selection strategy attractive.

In this example, the medium size fan (Strategy Three) has the highest initial cost, Table 5, reflecting the manufacturer's cost of a fan casing with a stabilisation ring. Operating costs fall between costs for Strategy One and Two, reflecting the efficiency of the medium-sized fan that is between those of the largest and smallest.

Stabilisation rings can reduce the fan's efficiency, due to the recirculating flow in the blade tip region. For fans intended for use at ambient temperature only, the reduction in efficiency can be significant. In this study, the authors have assumed that the fans associated with each strategy are designed in accordance with the requirements of EN 121013 (2002) and ISO 21927-3 (2006) for once-only emergency operation at $300^{\circ} \mathrm{C}$. The use of aluminium blade results in the blades expanding more rapidly then the steel casing as temperature rises. Consequently, the blade tip to casing clearance has to increase at ambient temperature to prevent it closing at high temperature. The increase in blade tip to casing gap from typically $0.25 \%$ of fan diameter (for ambient duty only) to $0.45 \%$ (for once-only $300^{\circ} \mathrm{C}$ emergency duty) reduces fan efficiency. In practice, the stabilisation ring does not reduce efficiency further when a fan has a large tip gap to facilitate high-temperature operation. Consequently, the fan that the authors used in this study confirms the general rule of thumb that larger fans are more efficient for a fixed duty point.

\section{Summary and Conclusions}

The experimental results are significant in that they provide insight into a likely reason for tunnel ventilation fans' inservice failure. In this study, the alternating stress level with fan operation in aerodynamic stall with a fitted stabilisation ring resulted in alternating stress increasing, and consequently, the mechanical safety factor reducing from 2.5 to 1.1 . This increase is significant within the context of a smoothly rising fan characteristic that provided little indication that alternating stress had increased.

The smoothly rising fan characteristic resulted in Bard [33] claiming that "unstable performance due to stalling is completely eliminated." As Bard conducted a purely aerodynamic programme, making no measurement of steady or alternating stress, we may assume that when Bard referred to "unstable performance" he was referring to unstable aerodynamic performance. However, the claim may have resulted in some fan designers assuming that mechanical stress would also remain stable.

A tunnel ventilation fan with a nonstalling blade angle classically exhibits a continually rising characteristic. In effect, the fan blade aerodynamic loading is light enough that the fan does not suffer a classical aerodynamic stall. Alternating stress in a fan blade with a nonstalling blade stagger angle when operated in the unstable region of the fan characteristic does increase compared to the same fan operating in the stable region. Mechanical safety factor reduces from 2.4 to 1.5 , and although any reduction in safety factor is undesirable, a safety factor of 1.5 is, nevertheless, high enough to make stalled operation possible, without suffering a fatigue-related mechanical failure.

The experimental results for both the stalling blade angle with fitted stabilisation ring and nonstalling blade angle with no stabilisation ring both result in mechanical safety factors that are less then the industry norm of 2.0. As such, we can regard both a stabilisation ring and nonstalling blade angle as methods to mechanically protect a tunnel ventilation fan in the event of an unforeseen stall event. If the fan application is one in which the fan will routinely drive into stall, then the prudent fan designer would increase the mechanical safety factor during stable operation to ensure that it did not fall below 2.0 during stalled operation. 
The practice of selecting tunnel ventilation fans to accommodate pressure pulses within the stable part of the fan characteristic avoids the associated mechanical risk with operating tunnel ventilation fans in the stalled condition. However, this approach requires the tunnel ventilation system designer to foresee how the tunnel will operate for the life of the ventilation system. The current practice of fitting platform screen doors to historic metros has significantly increased the magnitude of pressure pulses, with the consequent risk that tunnel ventilation fans that the pressure pulse did not previously drive into stall will occur.

Additionally, fans that are correctly selected to operate within the stable part of their characteristic at $100 \%$ speed will likely drive into stall if operated at $50 \%$ design speed and certainly drive into stall if operated at $25 \%$ design speed. In this research paper, the authors were able to demonstrate that for a tunnel ventilation fan with a stalling blade angle, without a fitted stabilisation ring, the mechanical factor of safety during stable operation is 2.3 . When they operated the same fan at half speed in an aerodynamically stalled condition, the mechanical factor of safety is 2.5 . As the mechanical factor of safety at half speed during stalled operation is higher then the mechanical factor of safety at full speed during stable operation, the authors conclude that users can operate this tunnel ventilation fan at half speed in an aerodynamically stalled condition without risk of a fatigue-related mechanical failure. At 25\% design speed, mechanical factors of safety in both stable and aerodynamically stalled operation are sufficiently high that there is no risk of a fatigue related mechanical failure.

The authors conducted the current study on a single fan, and it is, therefore, not possible to generalise the findings to all fan types. Despite the limitations of the current study, the sevenfold increase in alternating stress (from 2.27 MPa to $16 \mathrm{MPa}$ ) that the authors observed in the tested fan with a stalling blade angle and without a fitted stabilisation ring is consistent with the conclusions of Rippl's [1] research. Despite the difficultly in generalising results of the reported research, it is possible to observe that if the fan is to operate reliably, the mechanical design must account for the increase in alternating stress when the fan stalls. Not doing so could result in the fan's fatigue related mechanical failure.

When accounting for the increase in alternating stress when a fan stalls, and when assessing if that increase is acceptable, the tunnel ventilation fan designer must make an assumption about the maximum defect size in the fan blades and hub. Therefore, responsible fan manufacturers $100 \% \mathrm{X}$ ray inspect all fan blades and hub to verify that they do not exceed the fan designer's assumptions regarding maximum defect size.

Last, the authors conclude that the three fan selection strategies classically used by tunnel ventilation system designers each have specific advantages and disadvantages. The optimum fan selection strategy in a specific application will, therefore, depend on the impact of fan diameter on plant room cost and the relative importance of fan initial cost and fan-operating cost.

\section{Acknowledgments}

The authors conducted this research in the context of contract FW-DMA09-11 between Fläkt Woods Ltd and the Dipartimento di Ingegneria Meccanica e Aerospaziale, "Sapienza" University of Rome.

\section{References}

[1] A. Rippl, Experimentelle untersuchungen zuminstationaren betriebsverhahen an der stabilitarsgrenze eines mehrstufigen transsonischen verdichters, Ph.D. dissertation, RuhrUniversität Bochum, 1995.

[2] S. K. Ivanov, “Axial blower," Patent No. US 3,189,260, 1965.

[3] J. T. Gravdahl and O. Egeland, Compressor Surge and Rotating Stall: Modeling and Control, Springer, London, UK, 1999.

[4] I. J. Day and N. A. Cumpsty, "The measurement and interpretation of flow within rotating stall cells in axial compressors," Journal of Mechanical Engineering Science, vol. 20, pp. 101-114, 1978.

[5] E. M. Greitzer, "Review-axial compressor stall phenomena," Transactions of the ASME, Journal of Fluids Engineering, vol. 102, no. 2, pp. 134-151, 1980.

[6] F. K. Moore, "A theory of rotating stall of multistage axial compressors: parts I-III," Transactions of the ASME, Journal of Engineering for Gas Turbines and Power, vol. 106, no. 2, pp. 313-336, 1984.

[7] H. W. Emmons, C. E. Pearson, and H. P. Grant, "Compressor surge and stall propagation," Transactions of the ASME, vol. 77, pp. 455-469, 1955.

[8] N. A. Cumpsty, "Part-circumference casing treatment and the effect on compressor stall," ASME Paper No. 89-GT, 1989.

[9] S. Bianchi, A. Corsini, and A. G. Sheard, "Detection of stall regions in a low-speed axial fan. - part i: azimuthal acoustic measurements," in Proceedings of the 54th American Society of Mechanical Engineers Turbine and Aeroengine Congress, vol. 3, pp. 169-179, Glasgow, UK, June 2010.

[10] A. G. Sheard, A. Corsini, and S. Bianchi, "Method of detecting stall in an axial fan," Patent No. GB 2468571 B, 2010.

[11] A. G. Sheard, A. Corsini, and S. Bianchi, "Stall warning in a low-speed axial fan by visualization of sound signals," Journal of Engineering for Gas Turbines and Power, vol. 133, no. 4, Article ID 041601, pp. 1-10, 2011.

[12] C. C. Koch and L. H. Smith, "Loss sources and magnitudes in axial-flow compressors," Transactions of the ASME, Journal of Engineering and Power, vol. 98, no. 3, pp. 411-424, 1976.

[13] H. Saathoff and U. Stark, "Tip clearance flow induced endwall boundary layer separation in a single-stage axial-flow lowspeed compressor," ASME Paper No. 2000-GT-0501, 2000.

[14] S. A. Khalid, A. S. Khalsa, I. A. Waitz et al., "Endwall blockage in axial compressors," Transactions of the ASME, Journal of Turbomachinery, vol. 121, no. 3, pp. 499-509, 1999.

[15] H. Vo, C. S. Tan, and E. M. Greitzer, "Criteria for spike initiated rotating stall,” ASME Paper GT 2005-68374, ASME Turbo Expo, Reno-Tahoe, Nevada, Nev, USA, 2005.

[16] M. M. Bright, H. Qammar, H. Vhora, and M. Schaffer, "Rotating pip detection and stall warning in high-speed compressors using structure function," in Proceedings of AGARD RTO AVT Conference, Toulouse, France, May 1998.

[17] T. R. Camp and I. J. Day, "A study of spike and modal stall phenomena in a low-speed axial compressor," Journal of Turbomachinery, vol. 120, no. 3, article 393, 9 pages, 1998. 
[18] A. Deppe, H. Saathoff, and U. Stark, "Spike-type stall inception in axial flow compressors," in Proceedings of the 6th Conference on Turbomachinery, Fluid Dynamics and Thermodynamics, Lille, France, 2005.

[19] M. D. Hathaway, "Passive endwall treatments for enhancing stability," Report NASA/TM-2007-214409, 2007.

[20] G. L. Wilde, "Improvements in or relating to gas turbines," Patent No. 701,576, 1950.

[21] R. C. Turner, "Improvements in or relating to gas turbines," Patent No. 826,669, 1955.

[22] R. G. Griffin and L. H. Smith Jr., "Experimental evaluation of outer case blowing or bleeding of a single stage axial flow compressor, part I-design of rotor blowing and bleeding configurations," NASA Report CR-54587, 1966.

[23] E. E. Bailey and C. H. Voit, Some observations of effects of porous casings on operating range of a single axial-flow compressor rotor. Report NASA-TM-X-2120, 1970.

[24] D. C. Prince, D. D. Wisler, and D. E. Hilvers, "Study of casing treatment stall margin improvement phenomena," NASA Report CR-134552, 1974.

[25] D. C. Wisler and D. E. Hilvers, "Stator hub treatment study," NASA Report CR-134729, 1974.

[26] H. Takata and Y. Tsukuda, "Stall margin improvement by casing treatment-its mechanism and effectiveness," Journal of Engineering for Power, vol. 99, no. 1, article 121, 13 pages, 1977.

[27] E. M. Greitzer, J. P. Nikkanen, D. E. Haddad, R. S. Mazzawy, and H. D. Joslyn, "A fundamental criterion for the application of rotor casing treatment," Journal of Fluids Engineering, Transactions of the ASME, vol. 101, no. 2, pp. 237-243, 1979.

[28] S. G. Koff, R. S. Mazzawy, J. P. Nikkanen, and A. Nolcheff, "Case treatment for compressor blades," Patent No. US 5,282,718, 1994.

[29] S. J. Khalid, "Compressor endwall treatment," Patent No. US 5,520,508, 1996.

[30] N. A. Nolcheff, "Flow aligned plenum endwall treatment for compressor blades," Patent No. US 5,586,859, 1996.

[31] F. S. Gelmedov, E. A. Lokshtanov, L. E.-M. Olstain, and M. A. Sidorkin, "Anti-stall tip treatment means," Patent No. US 5,762,470, 1998.

[32] S. Karlsson and T. Holmkvist, "Guide vane ring for a return flow passage in axial fans and a method of protecting it," Patent No. US 4,602,410, 1986.

[33] H. Bard, "The stabilization of axial fan performance," in Proceedings of the Institution of Mechanical Engineers Conference C120/84 on the Installation Effects in Ducted Fan Systems (IMechE'84), pp. 100-106, 1984.

[34] Y. Miyake and T. Inaba, "Improvement of axial flow fan characteristics by means of separators," Journal of Turbomachinery Society of Japan, vol. 13, pp. 746-752, 1985.

[35] N. Yamaguchi, M. Ogata, and Y. Kato, "Improvement of stalling characteristics of an axial-flow fan by radial vaned air separators," Journal of Turbomachinery, vol. 132, no. 2, Article ID 021015, 10 pages, 2010.

[36] C. S. Kang, A. B. McKenzie, and R. L. Elder, "Recessed casing treatment effects on fan performance and flow field," ASME Paper No. GT-95-197, 1995.

[37] A. G. Sheard, A. Corsini, S. Minotti, and F. Sciulli, "The role of computational methods in the development of an aero-acoustic design methodology: application in a family of large industrial fans," in Proceedings of the 14th International Conference on Modelling Fluid Flow Technologies, pp. 71-79, Budapest, Hungary, September 2009.
[38] C. A. Wasserbauer, H. F. Weaver, and R. G. Senyitko, "NASA low-speed axial compressor for fundamental research," NASA Technical Memorandum 4635, 1995.

[39] W. C. Young, Roark's Formulas for Stress and Strain, McGrawHill, New York, NY, USA, 1989.

[40] W. Z. Gerber, "Calculation of the allowable stresses in iron structures," Bayer Architecture \& Engineering, vol. 6, pp. 101110, 1874. 

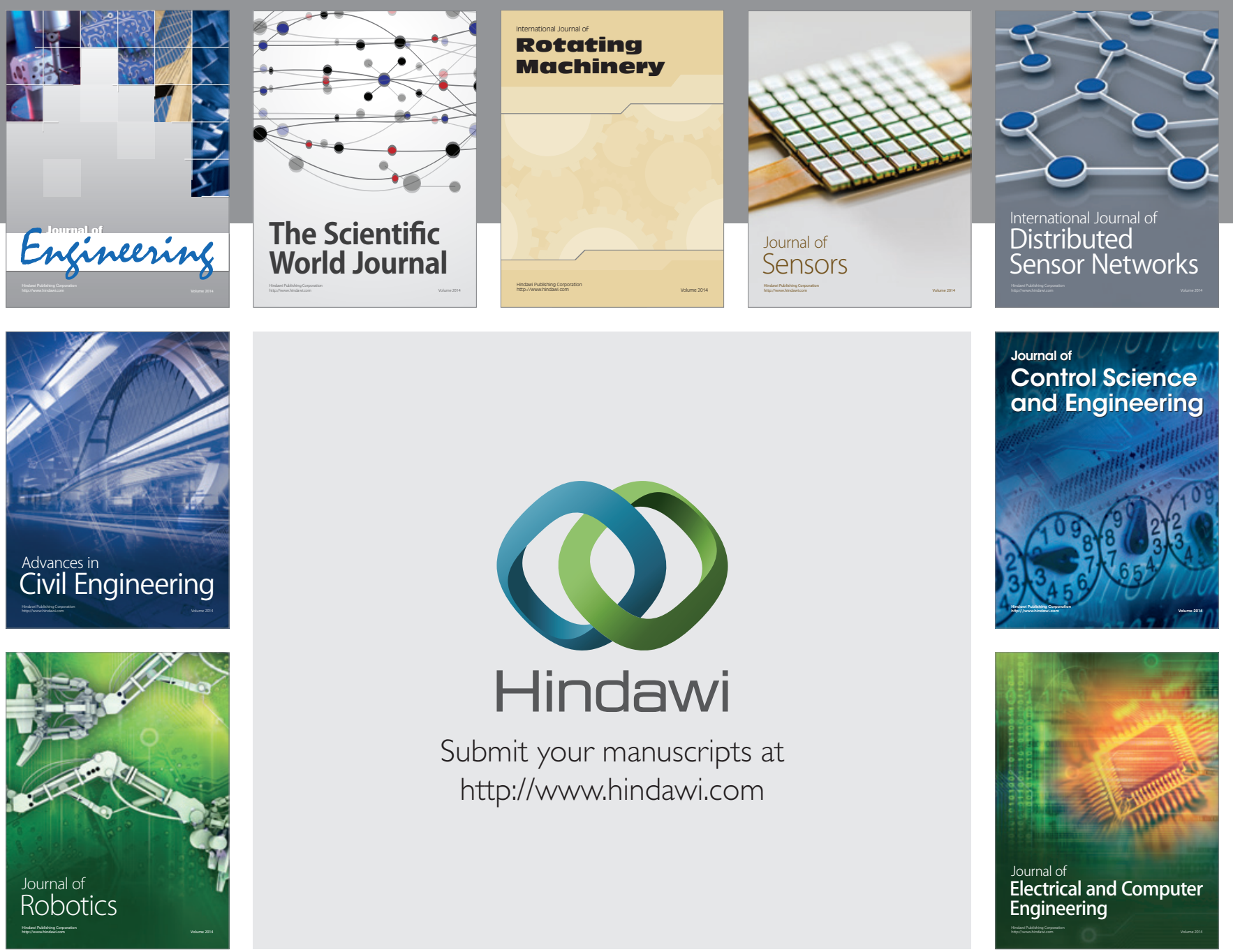

Submit your manuscripts at

http://www.hindawi.com
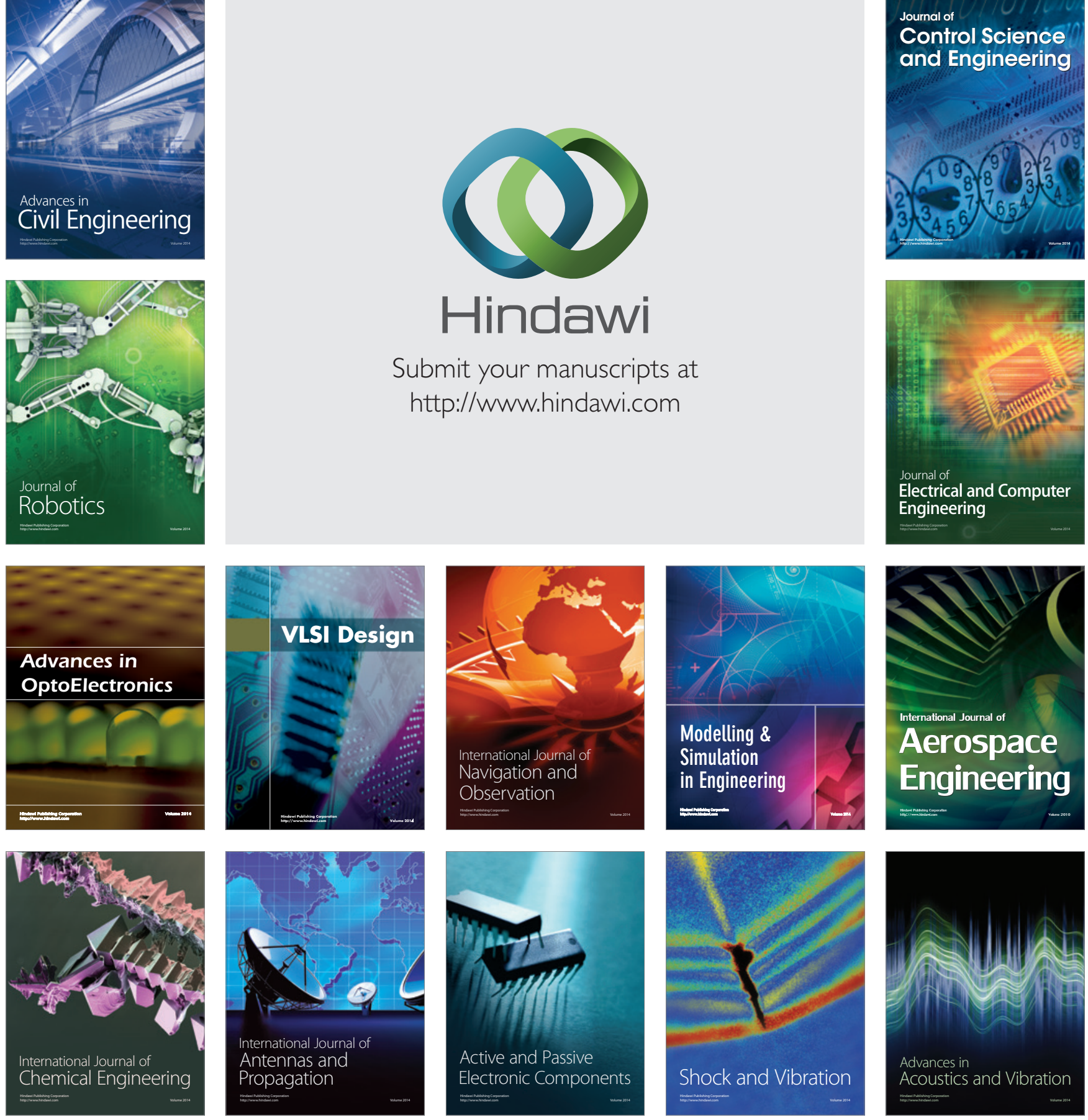